\title{
The Name of God
}

\section{Muller's and Cassirer's Linguistic View on Religion}

\author{
Xin $\mathrm{Li}$ \\ College of Foreign Languages and Literature \\ Wuhan Donghu University \\ Wuhan, China
}

\begin{abstract}
Muller believed that religion originated from human's understanding of the infinite. This capacity for perceiving infinite is latent in the human mind, and this potential germinates in the people's naming of natural phenomena which are semi-tangible or intangible. "The birth and growth of god is the birth and growth of his name". The development of abstract thinking ability of human has also gradually deepened human's understanding of the concept of divinity. Cassirer believed that when the tension between the human and the object world reached its limit, the tension was released in language and mythological thinking, and language and momentery deities came into being in the process. Language and mythological thinking interweave and promote each other in the process of human understanding, both of which are the starting points of human cultural. The two philosophers held different views on the relationship between language and religion, but they both put human language on an important position in epistemology.
\end{abstract}

Keywords-religion; language; mythological thinking

\section{INTRODUCTION}

Language, an important feature that distinguishes human from animals, is the basic tool for human thinking. As described in the Old Testament of the Bible, Genesis, before the becoming of the world, all was in chaos. And there came the God created the human world with language, "Then God said, Let there be light; and the light began", "And now God said, Let the waters below the vault collect in one place to make dry land appear. And so it was done". With words God created everything on the world in sequence. Without language, not only the material world but also the inner mental world of human beings will remain in chaos. Through language and concepts which also formed by language, human beings constantly reflect on their own existence and explore the existence of the outside world.

Religious belief is a unique spiritual and cultural phenomenon of human beings. How can god, a nonobjective being, come into the mind of human beings? This question attracts philosophers and scholars attention and induces them to devote their life to the course of solving it. However, history cannot be restored. People can only speculate the origin and development of religion based on the existing historical data and the history of human development. Among the various theories on the origin of religion, Ernst Cassirer and Max Muller believed that the creation and development of divinity are closely related to the development of language. But the two men hold different views on their relationship. Their language views on religion will be discussed respectively in the following chapters.

\section{MULLER'S LANGUAGE VIEW ON RELIGION}

In his Lectures on Origin and Growth of Religion, Muller points out that although each religion has its own object of belief, manifest their belief in different ways, and has gone through different development processes, its embryonic seeds are the same, and "the seed is the idea of infinite "1. Religion, the unique culture of human beings, is based on man's understanding of infinite. According to Muller, understanding the infinite is a potential possessed only by human beings. And he alleged that man's knowledge of the infinite predates the formation of the concept of the finite When the primitive people looked at the boundless sea, or trudged in the desert but couldn't reach its boundary, an overwhelming shocking had a great impact on their mind. This uncertain and insecure feeling triggers their perception of infinity. Then how did these perceptions form the concept of infinity, and how did they bring about the concept of divinity? Muller justified "the birth and growth of god equals the birth and growth of the name of god" ${ }^{2}$ by investigating Veda from India. We can get a glimps of how primitive people got " divine inspiration" from nature by exploring how they named these things.

\section{A. The Generation of Language}

Among many hypotheses about the origin of language, Muller holds that the language was created in the process of laboring. More specifically, the original form of language is the sound uttered natually by people when they were laboring. Muller used the becoing of the word "Mar" as an example to illustrate the development of language. Originally, the sound "Mar" was produced by an unconscious mouth movement as a primitive people polishing a stone or a piece of weapon. Later, with the repetition of this action, the sound "Mar" was fossilized to refer to certain things or actions and "Mar" became a fixed syllable. Later, with the expansion of

M, Muller, Lectures on Origin and Growth of Religion, Trans1. Z. Jin. Shanghai, pp20, 2010

M, Muller, Lectures on Origin and Growth of Religion, Trans1. Z. Jin. Shanghai, pp125, 2010 . 
scope of the life of primitive people, the syllable "Mar" was borrowed in other situations. Hence, the semantic function of "Mar" is also expanded. In order to distinguish its various semantic meaning and avoid the confusion in its usage, certain measures were employed. For example, stress and some other linguistic signs were added to distinguish the different meanings of "Mar" and classfied it into different lexical group. While, their common element, that was "Mar", becomes the root of the word and the root of the basic concept of the family group. Muller points out this process has illustrated the development of from using sound to express one's perception to expressing conception ${ }^{3}$.

\section{B. Emergence and Development of the Concept of Divinity}

With the creation of language, the original chaotic human thought has gradually taken the road of rational thinking. Then how does the creation of language promote the emergence and development of the concept of divinity? Modern psychological research has found that humans are used to projecting their perceptions to the outside world. "with the further acquaintanceship with the nature, primitive man assimilated the whole world around him. They found some similarity between the outside world and themselves, and gradually they transferred the voice which accompanied his actions to the activities around them." That is to say their naming of things reflects their understanding of things. For example, from different perspective of views, primitive people percepts different characteristics of rivers, and each characteristic gives them different feelings. Therefore, they used different names to refer rivers, like "runners", "cultivators" or "mothers". And all these names possess a simiar feature, that is they are personification of their own behaviors. However, when these things were first named by human beings, they use negative ways to emphasize their similarities with human behaviors. For example, "rivers are roaring and fighting, but they are not men. The mountains are indestructible, but they are not warriors". And it is this "non-likeness" that makes people feel the mystery and the sanctity behind this natural phenomanon.

In Veda, people praise the mountains, seas, rivers, the sky with different nouns or adjectives. For example, the sun is called Shavederi because of its dazzling light; Mithro for its bringing of light; Vishnu for its menifestion of time. For primitive people, the different properties of the sun mean new life, creation, the power of saving human beings from darkness and punishing evil and promoting good. So as founded in the Veda poets praised the sun of god with all their enthusiasm and in the most devout language. And for other natural phenomena they did the same thing. When employing different nouns or adjectives in praising these objects, they found certain common attributes of these natural phenomenon, such as living, immortal, eternal or bright. These attributes slowly become some common attributes of god, forming the concept of divinity.

The human mind is also prone to abstract synthesis. It brings a certain numbers of similar attributes together,

M, Muller, Lectures on Origin and Growth of Religion, Trans1. Z. Jin. Shanghai, pp116, 2010. through abstract and elimination of differences, similarities are preserved, and forms a general concept of a certain kind of object. In other poems of Rig Veda, these attributes of divinity are mainly attributed to Visvakarman and the Creator, who as the creator and ruler of the world possess all the attributes and powers of the divine could have. The ancient Aryan people's religion concepts developed step by step. At first, they sought the protection from mountains and rivers. Later, because the lack of complete control over the heavens, the uncertain feelings towards the sun and other untouchable objects led them to believe that there was some transdental, living force behind these natural phenomena ${ }^{4}$. They found Dyaus Pita in the sky and indra in the rain. However, "as long as there is something visible or concrete in the minds of the ancient Aryan worshippers, their inspiration about divinity will go far beyond the limits of actual observation" ${ }^{5}$. For instance, Indra is not a concrete substance in reality and is completely the product of human thought. While, he is thought to be more divine and placed higher than other gods. But he was also the first to arouse the suspicion from its admirers. In the late Rig Veda, doubts and denials to Indra are found. "If you want the prize, praise indra. If he really exists, you should praise him sincerely. Many people were saying, there is no Indra at all. Who has seen him? Who shall we praise?" At this point, the negation of Indra leads ancient Aryan to the road of going beyond "the infinite" and trying to explore the "ultimate reality" behind "the infinite". Looking back on the development of Indian religion, we can find that the ancient Aryan sensed the infinite and the sacred which they thought behind the natural phenomena. They wanted to know it and to hold it by naming it, they called it "the guardian", "the plough", "the mother", "Asura", "Aditya", and "Rita". In the end they realized that the infinity they believed in was "the sum of all things, and at the same time surpasses all things", that he was a pure being, "the lifeblood of all true beliefs".

\section{CASSIRER'S LINGUISTIC VIEW ON MYTHOLOGY}

Nearly hundred years western philosophors treated focused on mathematic, physics and other natural science as their main research focus, believing that only things could be proved science and logic is rational and meaningful, regarding the logic way of thinking as the most fundamental and most primitive way of thinking, "humanistic studies in philosophy are degraded into a homeless state". While, Cassirer holds the view that in the spiritual life of human beings, language, mythology, religion, art and other forms of humanities are no inferior to logical and scientific studies. They are the manesfestion of human spirit. He declares that myths may seem absurd and irrational, but as a matter of fact, they embody "comprehensible meaning" and constitute a unique conceptual system. Cassirer devotes himself to the study of language and myth. His fundamental purpose is to

M, Muller, Lectures on Origin and Growth of Religion, Trans1. Z. Jin. Shanghai, pp190, 2010.

M, Muller, Lectures on Origin and Growth of Religion, Trans1. Z. Jin. Shanghai, pp190, 2010.

M, Muller, Lectures on Origin and Growth of Religion, Trans1. Z. Jin. Shanghai, pp192, 2010. 
find out "what precedes logic" in human thought and establish "a systematic philosophy of human culture". In his Language and Myth, Cassirer said that language is the "organ" for human thinking, and is basically "metaphorical". So he came into a conclusion that all human knowledge and culture are not fundamentally based on the concept of logic and logical thinking but on metaphorical thinking. Metaphorical thingking which is "ahead of the concept and expression of logic " is the original and basic way of human thinking. "The starting point for the study of philosophy and epistemology is not, and should not be, the 'pure scientific study'---the late achievement of human intelligence, but the starting point of human intelligence -- language and myth"".

\section{A. The Emergence of Language and Mythological Thinking}

Traditional logic believes that conception is the starting point of the deduction of thinking, then where does conception come from? Actually it requires help from language. As is recorded in the Bible, God brought creatures to Adam and said, " and brought them unto Adam to see what he would call them: and whatsoever Adam called every living creature that was the name thereof". Just through naming all the things on the earth man brought the world to light. During the process of naming things the outside world perceived by sense organs has internalized as psychological world, a world full of ideas and meanings.

So, how does language happen? How did man name everything? Cassirer believed that language concepts and mythological thinking came from the same origin and could be found in people's intuitive interllectural and the primitive ability of subjective sense of feelings. When facing a sudden emotion or crisis, a primitive man would devote all his attention and energy to this one and only object ${ }^{8}$. However, in the mode of logical thinking, logical observation tends to expand outwards and place one perception into complex networks, that is, combining single perception with other perceptions and embedding them in the whole circle while trying to maintain their independence. In the mythological and linguistic thinking, the external world is not only observed and sensed in intensive concentration, but subjugates people with its simple directness and overwhelmed with fear, surprise and other emotions. At this time, "electricity strikes through the medium", the tension between the subject and the object, the emotion towards to outside world, are released through words or mythological images. And people's psychological emotion is objectified and externalized into the objective form of myth or speech, that is, the exclamation expressing emotion or instant god. Primitive people used exclamations to express their respect for any extraordinary, miraculous or frightening thing that caused them to fear, wonder, such as such "manitu" used by the alquincin and "murangu" by the Bantu. Therefore, we can say, in the initial form of language, exclamations and sacred ideas burst forth simultaneously.

\footnotetext{
E, Cassirer, Language and Myth, Trans1, X. Yu. Beijing, pp8,

1988.

E, Cassirer, Language and Myth, Trans1, X. Yu. Beijing, pp51,
}

\section{B. The Simultaneous Development of Language and Mythological Thinking}

Language and mythological thinking interweave and promote each other. With the development of human mind and culture, people's passive adaptation to the nature has changed into active participation in the external world, and human beings started to control the developmental process of events with their own will, forming some orderly and continuous activities which are periodic and regular. Human beings began to view the external world through selfprojection and based on their own behavioral cognition, and realize their initiative in conquering the world. Thus, in each of the branches of human activity came the "professional gods" representing such activities. And these professional gods are given different names according to their activities. These names limit the duties of the god, who is fixed in the field in which he was first born. However, if the names of these professional gods loses its original meaning due to phonetic changes, or loses its connection with the living language due to the aging of the etymology, the name will no longer refer to the original single activity but become a proper noun. The name was then appended to a personal concept, here came the birth of the personal god. And later on, the attributes originally belonging to each of the professional gods have been given to the specific personal god, so people began to refer to the personal god by the name of these professional gods. For example, in ancient Egyptian religion, the god Isis was called the "god of thousands of names" and "god of tens of thousands of names". And the more names are attached to this god, the greater is his divine power. The evolution and development of language in communication enriches the concept of god.

The naming activities also enable human beings to distinguish and recognize different things, and to set different attributes for different things. Names show the characteristis of things, and fix it in language. With the development of human mind moving forward, and the attributes and names of god become more and more diverse. On the other hand, language thinking also tends to be more abstract. This tendency to generalize language thinking prompts human beings to seek the supreme identity of the divine idea in these diverse gods. However, the supreme divinity could not be embodied with any attribute, for any attribute is a limit to its pure nature. At this time, the development of language provides a new means for mythological and religious thinking, that is, prepositions evoled from expressing a particular form of existence to expressing the concept of existence. All attributes of god were accumulated into the concept of "being". All separate, specific names of gods are given one name: the Being. God became a "pure being."

With time went on, when the concept of "I" was created, religious thinking requested a new category. People's selfknowledge was reflected in religion. God calls himself "I am here I am". "This self-expression turns objective reality into subjective existence. God is exalted to the height of the absolute. In Indian religions, the being of god and "I" become one. The Being is "I". At this time, "religious speculation has reached the transcendental domain, 
independent from the power of words and the guidance of language" ${ }^{\prime 9}$, and language can no longer express the identity of "subject" and "object", and have to resorts to negative expression. So at the time when religion tries to transcend language, that is the time when the development of religion has reached the apex of its intellectual development. Without the help of linguistic concepts, any attempt to think is futile. Thus it can be seen that language and myth interact with each other in the process of the development of the concept of divinity, which drives human beings to mature their understanding of the objective world and themselves.

\section{CONCLUSION}

In Lectures on Origin and Growth of Religion, Mueller shows the development of religion by studying the development of language in Veda by the research of linguistic comparison. Starting from the human understanding of the infinite, poems in Veda discloses the development of god from semi-touchable or non-touchable objects. Human understanding on the divinity enolves from the perception of infinite behind nature to the "infinite" in ontology. In this process, language plays an important role in promoting the concept on religion.

In Cassirer's view, both language and religiousmythological thinking come from the same resource: metaphorical thinking. Language and religious-mythological thinking originates from the same basic psychological activity, that is the absolute concentration of human attention under the stimulation of extreme emotions or crisis. In this process, due to the convergence of intuitive intellectural, the tension between the people's subjective thinking and the objective world reaches its peak, in the form of objectification and externalization, language and myth release this tension between the subject and object under the principle of "partial is the whole" in metophor theory. Here comes language and "momentery deities". Starting from the common point, in the later development, language and mythological thinking also infiltrate and interact with each other and absorb new life from each other.

In his speech on the Origin of Religion at the Royal Society in 1778, Muller's main goal was to use linguistics as evidence to correct the view that religion originated from fetishism and to explore the true origin of religion. By the beginning of the 20th century, when Cassirer wrote the book Language and Myth, his fundamental purpose was to discover "what precedes logical concepts and expressions", to excavate the true ontological basis of philosophy, and turn philosophical research from logical and scientific approach to the study of human culture. Although the purpose of the two studies is different, the research methods applied by Muller and Cassirer showed us the relationship between language and religion. As Humboldt said, "man lives with objects mainly in accordance with what language presents to him. Man wove language out of his own being, and in the

\footnotetext{
9 E, Cassirer, Language and Myth, Trans1, X. Yu. Beijing, pp97,
}

same process he put himself in the trap of language" 10 . Language helps human to construct the external objective world into the inside spiritual world. At the same time, language also connects these two worlds. It is a bridge between the subject and the objective world. On this bridge, the subject and the object frequently interact with each other. And religious belief, as a cultural phenomenon, can be integrated and produced in this interaction, absorbing nutrients and continuously sublimating, and influence on the subjective and objective world of human beings.

\section{REFERENCES}

[1] M, Muller, Lectures on Origin and Growth of Religion, Trans1. Z. Jin. Shanghai, pp20-197, 2010.

[2] E, Cassirer, Language and Myth, Trans1, X. Yu. Beijing, pp8-97, 1988.

[3] L.J, He, "Cassirer's Mythological Thinking", Journal of XiangNan College, Vol.3, 2005

[4] Y.H, Liu, "An Study on Cassirer's View on Linguistic Philosophy", Journal of NanChang University, Vol.1, 2007
10

E, Cassirer, Language and Myth, Trans1, X. Yu. Beijing, pp37, 